\title{
Malaria Related Neurocognitive Deficits and Behavioral Alterations
}

\section{OPEN ACCESS}

Edited by:

Laurent Rénia,

Nanyang Technological University,

Singapore

Reviewed by:

Celio Geraldo Freire-de-Lima, Federal University of Rio de Janeiro,

Brazil

Sara Salinas,

Institut National de la Santé et de la

Recherche Médicale (INSERM),

France

*Correspondence:

Pamela Rosa-Gonçalves pamelagoncalves@aluno.fiocruz.br

Specialty section:

This article was submitted to

Parasite and Host,

a section of the journal

Frontiers in Cellular and

Infection Microbiology

Received: 05 December 2021

Accepted: 31 January 2022

Published: 22 February 2022

Citation:

Rosa-Gonçalves $P$,

Ribeiro-Gomes FL and

Daniel-Ribeiro CT (2022) Malaria

Related Neurocognitive Deficits

and Behavioral Alterations.

Front. Cell. Infect. Microbiol. 12:829413.

doi: 10.3389/fcimb.2022.829413

\author{
Pamela Rosa-Gonçalves ${ }^{1,2,3 *}$, Flávia Lima Ribeiro-Gomes ${ }^{1,2}$ \\ and Cláudio Tadeu Daniel-Ribeiro ${ }^{1,2}$
}

${ }^{1}$ Laboratório de Pesquisa em Malária, Instituto Oswaldo Cruz, Fundação Oswaldo Cruz (Fiocruz), Rio de Janeiro, Brazil, ${ }^{2}$ Centro de Pesquisa, Diagnóstico e Treinamento em Malária, Fiocruz and Secretaria de Vigilância em Saúde, Ministério da Saúde, Rio de Janeiro, Brazil, ${ }^{3}$ Laboratório de Biologia, campus Duque de Caxias, Colégio Pedro Il, Duque de Caxias, Brazil

Typical of tropical and subtropical regions, malaria is caused by protozoa of the genus Plasmodium and is, still today, despite all efforts and advances in controlling the disease, a major issue of public health. Its clinical course can present either as the classic episodes of fever, sweating, chills and headache or as nonspecific symptoms of acute febrile syndromes and may evolve to severe forms. Survivors of cerebral malaria, the most severe and lethal complication of the disease, might develop neurological, cognitive and behavioral sequelae. This overview discusses the neurocognitive deficits and behavioral alterations resulting from human naturally acquired infections and murine experimental models of malaria. We highlighted recent reports of cognitive and behavioral sequelae of non-severe malaria, the most prevalent clinical form of the disease worldwide. These sequelae have gained more attention in recent years and therapies for them are required and demand advances in the understanding of neuropathogenesis. Recent studies using experimental murine models point to immunomodulation as a potential approach to prevent or revert neurocognitive sequelae of malaria.

Keywords: severe malaria, non-severe malaria, neurocognitive deficits, behavioral alterations, murine malaria

\section{INTRODUCTION}

Malaria, an important parasitic infectious disease since antiquity, remains a significant public health problem, being responsible for estimated 229 million cases and 409.000 deaths worldwide annually (World Health Organization, 2020). It is caused by protozoa of the genus Plasmodium and is transmitted by the bite of the female Anopheles mosquito. There are eight species causing human malaria: P. falciparum, P. vivax, P. malariae, P. ovale curtisi and P. ovale wallikeri (Sutherland et al., 2010), $P$. knowlesi, $P$. cynomolgi and $P$. simium, the last three being simian parasites responsible for zoonotic infections (Chin et al., 1965; Singh et al., 2004; Ta et al., 2014; Brasil et al., 2017a), and P. falciparum, which accounts for the great majority of cases and severe forms of the disease (Cox, 2010). In the early stages of infection, malaria may present with nonspecific symptoms of febrile syndromes (including nausea and diarrhea) before the emergence of the classic triad (fever, chills, sweating), often associated with headache. The disease may evolve, in case of falciparum malaria, to its severe forms such as cerebral malaria (CM), severe acute respiratory syndrome, severe malarial anemia, among others (Ashley et al., 2018). Although severe anemia is the most common 
complication of the disease, $\mathrm{CM}$ is the deadliest one, affecting mainly children up to 5 years old, pregnant and non-immune individuals (tourists and military) from non-endemic areas (Porta et al., 1993; Ashley et al., 2018; Ghazanfari et al., 2018).

The neuropathogenesis of CM involves brain intravascular sequestration of $P$. falciparum-parasitized red blood cells occurring through the expression of parasite-encoded $P$. falciparum erythrocyte membrane protein-1 (PfEMP-1) in protuberances of the infected red-cell surface that interacts with host adhesion receptors on endothelium, contributing to the inflammatory process (Lau et al., 2015). These events participate in the generation of blood flow impairment, endothelial dysfunction, intravascular coagulation, vascular occlusion, cerebral hypoxia, microglial activation, astrogliosis, disruption of the blood-brain barrier and neurotoxicity (Medana et al., 2002; Taylor et al., 2004; Dorovini-Zis et al., 2011; Schiess et al., 2020).

Post treatment long-term neurocognitive deficits, including in multiple areas of cognitive function, and behavioral alterations ${ }^{1}$ are related to severe malaria, mainly CM (Bangirana et al., 2014; Ssenkusu et al., 2016; Conroy et al., 2019a). Nevertheless, cognitive deficits and behavioral alterations have also been associated to the non-severe presentations of the disease (Vitor-Silva et al., 2009; Fink et al., 2013; Tapajós et al., 2019).

The aim of this mini review is to provide an overview on the state of art and on the available knowledge in the literature on neurocognitive and behavioral damage associated to malaria. There are few articles on the subject and some of them have limitations, due to involving human beings, having been carried out in areas lacking adequate infrastructure, or having critical design or methodological aspects. Although a detailed analysis on the structure of the cited articles is out of this mini review scope, we have tried to indicate points of concern deserving attention whenever appropriate.

\section{NEUROCOGNITIVE AND BEHAVIORAL SEQUELAE OF SEVERE MALARIA}

Individuals with $\mathrm{CM}$ treated with artesunate, a potent antimalarial treatment that promotes a rapid decline in parasitemia and recovery (Dondorp et al., 2010), still progress to death in about 15-25\% of cases (Bruneel, 2019). Unfortunately, approximately $25 \%$ of survivors develop neurocognitive and behavioral sequelae (Bruneel, 2019). Several studies have associated the most varied neurological sequelae, cognitive deficits and behavioral alterations, as well as predisposition to mental disorders in children (Carter et al., 2005a; Carter et al., 2005b; Carter et al., 2006; Idro et al., 2006;

\footnotetext{
${ }^{1}$ Neurologic sequelae: consist of functional loss in motor, speech, vision, and hearing domains, as well as epilepsy; Neurocognitive deficits: a neurological and/ or cognitive impairment involving specific brain-located neural phenomena; Cognitive deficits: decrease in skill related to broad sense of consciousness (how one perceives, remembers things, judges oneself); Behavioral alterations: behavior changes, including inattentiveness, hyperactivity, impulsive/ aggressive behaviors and risk of manifestation of mental health disorders.
}

Boivin et al., 2007; Birbeck et al., 2010; Bangirana et al., 2011; Idro et al., 2016; Ssenkusu et al., 2016; Brim et al., 2017; Langfitt et al., 2019) and adults (Richardson et al., 1997; Varney et al., 1997; Laverse et al., 2013; Peixoto and Kalei, 2013) with CM (Figure 1).

Among children up to five years old, a greater risk for the development of impairment in motor skills, receptive and expressive language, visual reception and social interaction has been identified (Brim et al., 2017; Ouma et al., 2021). Multiple seizures, prolonged coma and intracranial hypertension during $\mathrm{CM}$ appear to be related to the risk of neurological sequelae including epilepsy (Idro et al., 2004; Idro et al., 2006; Kariuki et al., 2011). CM does also result in deficits in multiple cognitive domains such as attention and associative memory (Bangirana et al., 2014) and increased risk of mental health disorders (Idro et al., 2016).

The dynamics of malaria deficits can be affected by several factors, such as infection at different stages of neurodevelopment, number of previous malaria episodes, methodology used to assess the neurocognitive outcomes, and follow-up time. Although some neurological sequelae of CM in children, such as hypotonia, cortical blindness, tremors and aphasia recover over time (Boivin et al., 2007; John et al., 2008; Dondorp et al., 2010), other such as hemiplegia, paresis, seizures, language deficits and, especially, cognitive impairment in memory, nonverbal function and behavioral alterations may persist (Carter et al., 2006; Birbeck et al., 2010; Oluwayemi et al., 2013; Severe Malaria, 2014) (Table 1) for up to nine years after an episode of CM (Carter et al., 2005a).

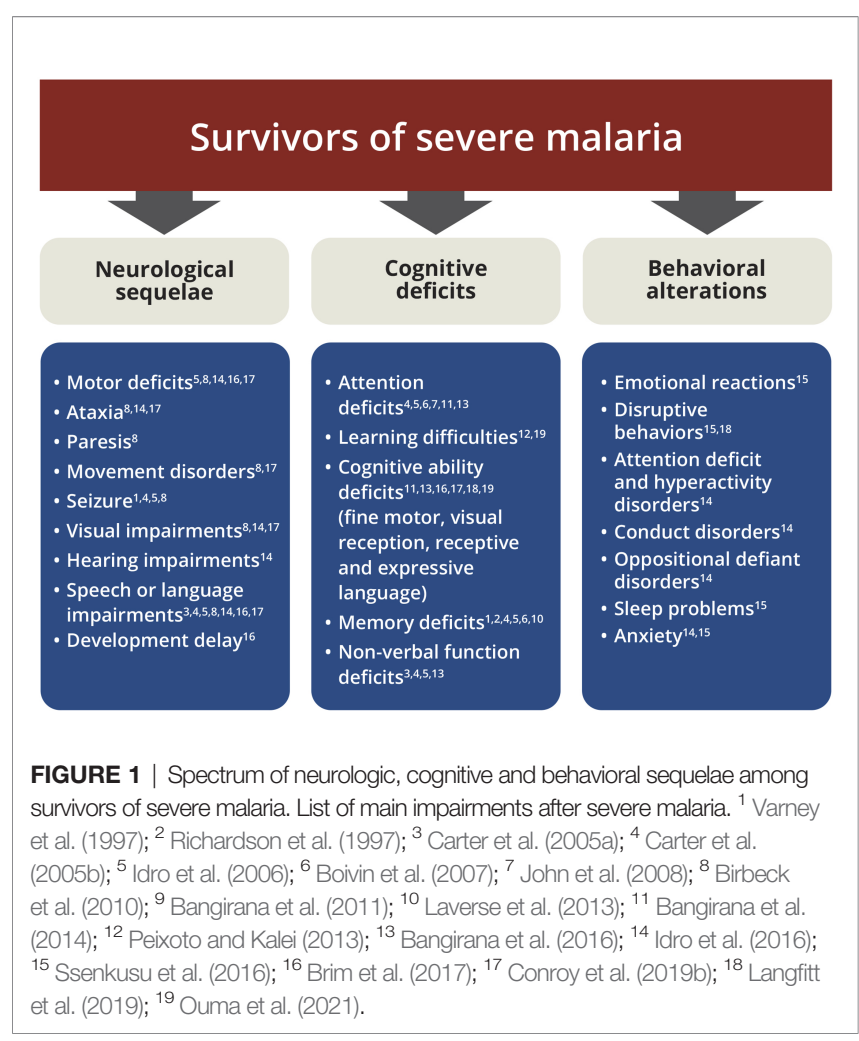


TABLE 1 | Detection and persistence of neurocognitive and behavioral alterations in children with cerebral malaria.

\begin{tabular}{|c|c|c|c|c|c|c|}
\hline \multirow[t]{2}{*}{ Outcomes } & \multirow[t]{2}{*}{ Impairments at discharge } & \multicolumn{3}{|c|}{ Months* } & \multirow[t]{2}{*}{$\mathbf{n}$} & \multirow[t]{2}{*}{ Reference } \\
\hline & & 6 & 12 & 24 & & \\
\hline \multicolumn{7}{|l|}{ Neurologic sequelae } \\
\hline Neurologic deficits & ++++++ & + & + & + & 232 & Conroy et al. (2021) \\
\hline \multirow[t]{2}{*}{ Motor } & +++++ & & + & & 173 & Idro et al. (2016) \\
\hline & +++++ & & & + & 225 & Conroy et al. (2019b) \\
\hline Movement disorders & + & & & + & 225 & Conroy et al. (2019b) \\
\hline \multirow[t]{2}{*}{ Visual } & ++ & & - & & 173 & Idro et al. (2016) \\
\hline & ++ & & & - & 225 & Conroy et al. (2019b) \\
\hline Hearing & + & & - & & 173 & Idro et al. (2016) \\
\hline \multirow[t]{3}{*}{ Speech and/or language } & ++ & & + & & 131 & Oluwayemi et al. (2013) \\
\hline & ++ & & - & & 173 & Idro et al. (2016) \\
\hline & +++ & & & + & 225 & Conroy et al. (2019b) \\
\hline Paresis & + & & + & & 131 & Oluwayemi et al. (2013) \\
\hline Seizure & + & & + & & 131 & Oluwayemi et al. (2013) \\
\hline Hyporeflexia or Babinski sign & +++ & & & - & 225 & Conroy et al. (2019b) \\
\hline \multirow[t]{2}{*}{ Ataxia and/or gait problems } & +++ & & - & & 173 & Idro et al. (2016) \\
\hline & ++++ & & & - & 225 & Conroy et al. (2019b) \\
\hline \multicolumn{7}{|l|}{ Cognitive deficits } \\
\hline MSEL & + & + & + & & 80 & Bangirana et al. (2016) \\
\hline KABC or MDAT & + & + & + & & 85 & Langfitt et al. (2019) \\
\hline RBMTC & & & & + & 152 & Carter et al. (2006) \\
\hline Memory deficits & + & & + & + & 131 & Oluwayemi et al. (2013) \\
\hline Attention & + & $t^{\star *}$ & & ++++ & 38 & John et al. (2008) \\
\hline \multicolumn{7}{|l|}{ Behavioral alterations } \\
\hline Increased risk of expression of mental disorders & - & - & +++ & - & 173 & Idro et al. (2016) \\
\hline Behavioral dysfunctions & + & + & + & + & 100 & Ssenkusu et al. (2016) \\
\hline
\end{tabular}

Long-term cognitive ability deficits are also observed in children after severe malarial anemia (Bangirana et al., 2014; Conroy et al., 2019a). Severe anemia might affect the overall cognitive ability related to neurocognitive domains for fine motor scales, visual reception, receptive and expressive languages (Bangirana et al., 2014; Bangirana et al., 2016). Furthermore, acute kidney injury, a complication of severe malaria, is a risk factor for long-term neurocognitive impairment and behavioral problems in children with severe malarial anemia and cerebral malaria in overall cognitive ability (Conroy et al., 2019b), socio-emotional (aggressive behavior) and executive functions (Hickson et al., 2019).

Murine models have made invaluable contributions to malaria research (Lou et al., 2001). Different strains of mice infected by different species of plasmodia reproduce different forms of the disease depending on the combination of parasite and host, exhibiting susceptibility or resistance to severe forms. Neurologic, cognitive and behavioral deficits observed in malaria patients are reproduced in murine model of experimental CM (ECM). Infection of C57BL/6 and Swiss mice with Plasmodium berghei, ANKA strain (Grau et al., 1990; Martins et al., 2009; Martins et al., 2016), or Swiss mice with the lethal strain of P. yoelli (Li et al., 2001; Reis et al., 2010) are also models of ECM.

C57BL/6 mouse model infected with $P$. berghei ANKA is the classic reference for the study of ECM (Grau et al., 1990). The absence of a protein analogous to PfEMP-1, which binds to ligands overexpressed by influence of inflammatory cytokines on vessel endothelium in $P$. berghei, contributes to a limited sequestration of parasitized erythrocytes in the murine cerebral microvasculature. This model has, nonetheless, many characteristics that resemble human CM (Brian De Souza and Riley, 2002; De Niz and Heussler, 2018; Ghazanfari et al., 2018). Three days after infection (D3), low levels of parasitemia are measured, which gradually increase during the course of the infection. At D4, a slight adhesion of few leukocytes to the cerebral microvasculature may begin, with minimal presence of edema restricted to some punctual areas of the brain (Potter et al., 2006). Clinical neurological signs are identified from D5 on, with the establishment of a clear neurological syndrome at D6, including vascular inflammation, endothelial activation, rupture of the blood-brain barrier, edema and punctiform hemorrhage in parts of the brain, in addition to the set of neurocognitive sequelae and behavioral alterations assessable in behavioral tests in the acute phase and after recovery from ECM (Brian De Souza and Riley, 2002; Hunt et al., 2006; Potter et al., 2006; Desruisseaux et al., 2008; Dai et al., 2010; Reis et al., 2010; Lacerda-Queiroz et al., 2010; Martins et al., 2010; De Miranda et al., 2011; Reverchon et al., 2017; Ghazanfari et al., 2018; Lima et al., 2020). Generally, between days 6 and 9 the animals die (Martins et al., 2010).

During acute ECM, C57BL/6 mice infected with P. berghei ANKA exhibit motor impairment. In the course of acute 
infection, mice do also present cognitive deficits in object recognition test of working memory (Desruisseaux et al., 2008), anxiety-like behavior in elevated plus maze test (De Miranda et al., 2011) and depressive-like behavior in tail suspension and forced swim tests (Lima et al., 2020). Nonetheless and most important, specific neurological sequelae, including poor performance in balance beam test to evaluate motor coordination, are clearly present as sequelae after treatment of ECM (Dai et al., 2010; Reis et al., 2010). Cognitive deficits in multiple memory impairment (habituation, aversive and recognition memories) and behavioral alterations (depressive-like behavior) are also reported after CM (Reis et al., 2010; Lima et al., 2020).

Some experimental murine models, non-susceptible to the development of experimental CM, are useful to reproduce severe forms of non-cerebral malaria, for instance: P. berghei NK65 infected $\mathrm{C} 57 \mathrm{BL} / 6$ mice are used as an experimental model to investigate acute respiratory distress syndrome in malaria (Van Den Steen et al., 2010; Scaccabarozzi et al., 2018), while BALB/c mice infected with $P$. berghei ANKA compose a model of severe anemia and severe placental malaria (Neres et al., 2008; De Niz and Heussler, 2018). However, cognitive deficits were not registered in most of these experimental murine models of severe forms other than cerebral malaria (Reis et al., 2010; Freeman et al., 2016). Only a minor occurrence of neurological alterations of locomotor activity and autonomic function was observed in $\mathrm{BALB} / \mathrm{c}$ mice infected with $P$. berghei ANKA (Reis et al., 2010), as well as cognitive injury in the offspring of infected pregnant BALB/c mice (McDonald et al., 2015).

\section{COGNITIVE AND BEHAVIORAL SEQUELAE OF NON-SEVERE MALARIA}

Cognitive and behavioral deficits are also observed after episodes of non-severe malaria in individuals from diverse $P$. falciparum and $P$. vivax endemic areas (Fernando et al., 2003; Vitor-Silva et al., 2009; Thuilliez et al., 2010; Fink et al., 2013; Vorasan et al., 2015; Brasil et al., 2017b; Tapajós et al., 2019). The reported effects have been found in individuals who had uncomplicated febrile episodes of malaria (Vitor-Silva et al., 2009; Vorasan et al., 2015; Brasil et al., 2017b; Tapajós et al., 2019) and even asymptomatic infections (Al Serouri et al., 2000; Nankabirwa et al., 2013; Clarke et al., 2017).

Impairments in the school performance associated with language and logical reasoning in mathematics have been identified in children from Brazil and Sri Lanka after non-severe malaria (Fernando et al., 2003; Vitor-Silva et al., 2009). In addition, children with more than five episodes performed less well than children who had up to three febrile attacks (Fernando et al., 2003). Additional studies with different ranges in the number of past episodes of malaria can confirm and reinforce the observation of a quantitative effect of malaria on the cognitive-behavioral performance of infected children. School performance was evaluated during a nine-month follow-up (Vitor-Silva et al.,
2009). Tapajós et al. (2019) clearly demonstrated that an episode of non-severe malaria, caused by $P$. vivax, was a determining factor - independent of the socioeconomic status, family stimulus and child's health status - in triggering cognitive impairment in children aged two to seven years. In Zambia and Uganda, episodes of malaria (with or without anemia) were associated with impaired cognitive ability in children (Fink et al., 2013; Boivin et al., 2016). Fink et al. (2013) point out that children's exposure to malaria was associated with reduced socio-emotional development. It is worth mentioning that the effect size was not shown in this study, which did not evaluate individual infection rates, but rather used national data.

On the other hand, classic murine models of non-severe malaria as C57BL/6 mice infected with $P$. chabaudi and Swiss with $P$. yoelii (non-lethal) were unable to reveal the presence of cognitive impairment (Reis et al., 2010; Guha et al., 2014). Behavioral alterations, such as anxiety-like behavior and social interaction deficits, are observed during the course of non-severe malaria (D9) in C57BL/6 mice infected by $P$. chabaudi adami (Guha et al., 2014). These alterations may be, however, at least partially due to the inflammatory state of animal during the course of the ongoing infection. In this model, infection also predisposes to enhanced post-stress anxiety-like responses when non-severe malaria occurs at a young age (Guha et al., 2020).

More recently, De Sousa et al., (2018) infected C57BL/6 mice with $P$. berghei ANKA (the classic model of experimental CM), treating mice at D4, before any neurological manifestation of CM. This model proved to be useful for detecting cognitive sequelae and late (D92) behavioral alterations following (82 days after parasite clearance) a single episode of non-severe malaria (De Sousa et al., 2021).

\section{THERAPEUTIC APPROACHES TO NEUROCOGNITIVE AND BEHAVIORAL SEQUELAE IN MALARIA}

To date, no effective therapy for the cognitive and behavioral sequelae of malaria is available. The lack of an effective therapy is associated with an incomplete understanding of the mechanisms involved in pathogenesis of cognitive and behavioral sequelae, especially in non-severe malaria. This knowledge is important to the development of rational therapies, directed to specific targets.

While several clinical studies to treat CM appeared promising for focusing on specific targets of pathogenesis, as sequestration of parasitized erythrocytes in the microvasculature, inflammation, coagulation, endothelial function and oxidative stress, they have not been successful in reducing neurologic sequelae (Lell et al., 2010; Mwanga-Amumpaire et al., 2015; Schiess et al., 2020). Some approaches have even aggravated these sequelae (Warrell et al., 1982; Van Hensbroek et al., 1996; Akech et al., 2006).

In addition, many studies investigating adjuvant therapies in CM do not assess the effects on neurocognitive sequelae. Although antimalarials may not be considered an approach to treat these sequelae, Conroy et al. (2021) recently showed that 
treatment of severe malaria with derivatives of artemisinin in children resulted in a significant reduction in mortality and in neurological deficits, associated with improvement in long-term behavioral alterations compared to quinine treatment. The absence of effect on overall cognition, attention and memory but a specific improvement in the executive function impairment, revealed by the BRIEF (Behaviour Rating Inventory of Executive Function) test observed by the authors, suggest that antimalarials may have distinct impacts on different categories of sequelae. Treatment of cognitive deficits remains a challenge. Some studies showed an expected positive effect of preventive malaria regimens on cognitive function of chronically exposed individuals in endemic areas (Cohee et al., 2020).

Several in vivo experimental studies have performed interventions - before infection or associated with antimalarial treatment - in an attempt to improve clinical response, increase survival and reduce neurocognitive and behavioral impairments (Varo et al., 2018; Gul et al., 2021). Serghides et al. (2014) got compelling effects of rosiglitazone, a PPARy agonist, as an adjuvant treatment of ECM. This treatment ameliorated recognition memory, reduced endothelial activation and oxidative stress, and increased neurotrophic factors (Varo et al., 2018). Currently the neurocognitive impact of this approach on CM is being accessed in a clinical trial. Lima et al. (2020) obtained promising results administrating mesenchymal stem cells (MSC) as adjuvant therapy to chloroquine at day 6 of infection, for ECM. Treatment with a single dose of MSC has protected infected mice against vascular damage and improved depressive-like behavior. Witschkowski et al. (2020) reported that bacillus Calmette-Guérin (BCG) vaccination given 10 or 30 days before infection protected mice from developing clinical symptoms of ECM and improved survival associated with immunosuppressive mechanisms. De Miranda et al. (2017) registered that treatment with MK801, a N-methil-D-aspartate (NMDA) receptor antagonist, before signs of ECM (from D3 to the end of antimalarial chloroquine treatment) prevented long-term memory impairment and depressive-like behavior.

Since diagnosis of CM does occur when the patient's condition is severe, the period required for the introduction of the treatment may not be sufficient for its effectiveness and the adjuvant approaches quoted above may have a very restricted therapeutic window (Idro et al., 2010). In view of these limitations, emphasis should be given to studies approaching the treatment of already established neurocognitive impairments. Neuroinflammation is a hallmark of neurocognitive and behavioral impairments of malaria and may result from peripheral inflammation (Sankowski et al., 2015). Therefore, immunomodulatory approaches hold promise for alleviating or stopping long-term damage.

Cognitive rehabilitation of severe malaria survivors through computerized training has shown an immediate improvement in some neuropsychological and behavioral parameters in children in Africa (Bangirana et al., 2009; Boivin et al., 2019). However, this approach in patients who have survived severe malaria may be limited by the need of specific diagnosis, long-term follow-up and information on how long this effect will last. Another limitation to the use of such approach is that it requires specific computer systems, often unavailable in endemic areas of developing countries (Boivin et al., 2019).

In the last few years, evidence has accumulated pointing to the ability of immune stimuli to modulate neurogenesis, synaptic plasticity, in addition to cognitive and behavioral function (Xia et al., 2014; Li et al., 2015; Li et al., 2016; Yang et al., 2016; Qi et al., 2017; Yang et al., 2020; De Sousa et al., 2021). These findings support the concept of consistent communication and interrelationship between the nervous and immune systems, as plastic and cognitive systems (Jerne and Cocteau, 1984; Pert et al., 1985; Cohen, 1992; Sawada et al., 1993; Josefsson et al., 1996; Amenta et al., 2002; McKenna et al., 2002; Daniel-Ribeiro and Martins, 2017) and the use of immunomodulation as a promising approach in the treatment of neurocognitive and behavioral sequelae of infectious diseases.

In this context, our research group has been investigating the effect of immune stimuli on neurocognition. Active immunization of both healthy and $P$. berghei ANKA infected C57BL/6 mice using different integrated stimuli (elicitors of the Th2 response) improved recognition memory in homeostasis, recovered late deficits in cognitive function and inhibited the manifestation of an anxiety-like phenotype caused by a unique episode of non-severe malaria (De Sousa et al., 2021).

\section{CONCLUSIONS}

In summary, accumulating evidence has revealed that malaria might lead to significant global cognitive impairment and behavioral alterations, even after non-severe episodes, that might persist for years. Neurological sequelae, however, seem to be restricted to severe malaria. These neurocognitive and behavioral sequelae of malaria lack specific and effective treatment. Results obtained in a few well conducted recent studies highlight the potential of immunomodulation as a cognitive enhancement strategy to treat cognitive and behavioral sequelae of malaria.

\section{AUTHOR CONTRIBUTIONS}

PR-G drafted the manuscript and PR-G, FR-G and CD-R reviewed, edited and prepared its final version. All authors read and approved the submitted version.

\section{FUNDING}

FR-G and CD-R are supported by CNPq, Brazil, through a Productivity Research Fellowship, and CD-R is a "Cientista do Nosso Estado" by Faperj. The Laboratório de Pesquisa em Malária, Instituto Oswaldo Cruz (IOC), Fiocruz is an Associated Laboratory of the Instituto Nacional de Ciência e Tecnologia (INCT) in Neuroimmunomodulation supported by the CNPq, and of the Rio de Janeiro Neuroinflammation Network financed by Faperj. 


\section{ACKNOWLEDGMENTS}

PR-G is grateful to the Postgraduate Program in Parasite Biology of the Instituto Oswaldo Cruz (IOC), Fiocruz, for the academic support, and to Conselho Nacional de Desenvolvimento Cientifico

\section{REFERENCES}

Akech, S., Gwer, S., Idro, R., Fegan, G., Eziefula, A. C., Newton, C. R. J. C., et al. (2006). Volume Expansion With Albumin Compared to Gelofusine in Children With Severe Malaria: Results of a Controlled Trial. PloS Clin. Trials 1, e21. doi: 10.1371/journal.pctr.0010021

Al Serouri, A. W., Grantham-McGregor, S. M., Greenwood, B., and Costello, A. (2000). Impact of Asymptomatic Malaria Parasitaemia on Cognitive Function and School Achievement of Schoolchildren in the Yemen Republic. Parasitology 121, 337-345. doi: 10.1017/S0031182099006502

Amenta, F., El-Assouad, D., Mignini, F., Ricci, A., and Tayebati, S. K. (2002). Neurotransmitter Receptor Expression by Peripheral Mononuclear Cells: Possible Marker of Neuronal Damage by Exposure to Radiations. Cell. Mol. Biol. (Noisy-le-grand). 48, 415-421.

Ashley, E. A., Pyae Phyo, A., and Woodrow, C. J. (2018). Malaria. Lancet 391, 1608-1621. doi: 10.1016/S0140-6736(18)30324-6

Bangirana, P., Giordani, B., John, C. C., Page, C., Opoka, R. O., and Boivin, M. J. (2009). Immediate Neuropsychological and Behavioral Benefits of Computerized Cognitive Rehabilitation in Ugandan Pediatric Cerebral Malaria Survivors. J. Dev. Behav. Pediatr. 30, 310-318. doi: 10.1097/DBP.0b013e3181b0f01b

Bangirana, P., Musisi, S., Boivin, M. J., Ehnvall, A., John, C. C., Bergemann, T. L., et al. (2011). Malaria With Neurological Involvement in Ugandan Children: Effect on Cognitive Ability, Academic Achievement and Behaviour. Malar. J. 10, 334. doi: 10.1186/1475-2875-10-334

Bangirana, P., Opoka, R. O., Boivin, M. J., Idro, R., Hodges, J. S., and John, C. C. (2016). Neurocognitive Domains Affected by Cerebral Malaria and Severe Malarial Anemia in Children. Learn. Individ. Differ. 46, 38-44. doi: 10.1016/ j.lindif.2015.01.010

Bangirana, P., Opoka, R. O., Boivin, M. J., Idro, R., Hodges, J. S., Romero, R. A., et al. (2014). Severe Malarial Anemia Is Associated With Longterm Neurocognitive Impairment. Clin. Infect. Dis. 59, 336-344. doi: 10.1093/cid/ ciu293

Birbeck, G. L., Molyneux, M. E., Kaplan, P. W., Seydel, K. B., Chimalizeni, Y. F., Kawaza, K., et al. (2010). Blantyre Malaria Project Epilepsy Study (BMPES) of Neurological Outcomes in Retinopathy-Positive Paediatric Cerebral Malaria Survivors: A Prospective Cohort Study. Lancet Neurol. 9, 1173-1181. doi: 10.1016/S1474-4422(10)70270-2

Boivin, M. J., Bangirana, P., Byarugaba, J., Opoka, R. O., Idro, R., Jurek, A. M., et al. (2007). Cognitive Impairment After Cerebral Malaria in Children: A Prospective Study. Pediatrics 119:e360-e366. doi: 10.1542/peds.2006-2027

Boivin, M. J., Nakasujja, N., Sikorskii, A., Ruiseñor-Escudero, H., Familiar-Lopez, I., Walhof, K., et al. (2019). Neuropsychological Benefits of Computerized Cognitive Rehabilitation Training in Ugandan Children Surviving Severe Malaria: A Randomized Controlled Trial. Brain Res. Bull. 145, 117-128. doi: 10.1016/j.brainresbull.2018.03.002

Boivin, M. J., Sikorskii, A., Familiar-Lopez, I., Ruiseñor-Escudero, H., Muhindo, M., Kapisi, J., et al. (2016). Malaria Illness Mediated by Anaemia Lessens Cognitive Development in Younger Ugandan Children. Malar. J. 15, 210. doi: 10.1186/S12936-016-1266-X

Brasil, P., Zalis, M. G., de Pina-Costa, A., Siqueira, A. M., Júnior, C. B., Silva, S., et al. (2017a). Outbreak of Human Malaria Caused by Plasmodium Simium in the Atlantic Forest in Rio De Janeiro: A Molecular Epidemiological Investigation. Lancet Glob. Heal. 5, e1038-e1046. doi: 10.1016/S2214-109X(17)30333-9

Brasil, L. M. B. F., Vieira, J. L. F., Araújo, E. C., Piani, P. P. F., Dias, R. M., Ventura, A. M. R. S., et al. (2017b). Cognitive Performance of Children Living in Endemic Areas for Plasmodium Vivax. Malar. J. 16, 370. doi: 10.1186/S12936017-2026-2

Brian De Souza, J., and Riley, E. M. (2002). Cerebral Malaria: The Contribution of Studies in Animal Models to Our Understanding of Immunopathogenesis. Microbes Infect. 4, 291-300. doi: 10.1016/S1286-4579(02)01541-1 e Tecnológico $(\mathrm{CNPq})$ and IOC for MSc and doctoral fellowships. The text of this manuscript originated in a theoretical chapter of the MSc dissertation of PR-G. The authors are thankful to Fernando Vasconcelos for designing the final version of Figure 1.

Brim, R., Mboma, S., Semrud-Clikeman, M., Kampondeni, S., Magen, J., Taylor, T., et al. (2017). Cognitive Outcomes and Psychiatric Symptoms of Retinopathy-Positive Cerebral Malaria: Cohort Description and Baseline Results. Am. J. Trop. Med. Hyg. 97, 225-231. doi: 10.4269/ajtmh.17-0020

Bruneel, F. (2019). Human Cerebral Malaria: 2019 Mini Review. Rev. Neurol. (Paris). 175, 445-450. doi: 10.1016/j.neurol.2019.07.008

Carter, J. A., Lees, J. A., Gona, J. K., Murira, G., Rimba, K., Neville, B. G. R., et al. (2006). Severe Falciparum Malaria and Acquired Childhood Language Disorder. Dev. Med. Child Neurol. 48, 51-57. doi: 10.1017/S0012162206000107

Carter, J. A., Mung'ala-Odera, V., Neville, B. G. R., Murira, G., Mturi, N., Musumba, C., et al. (2005a). Persistent Neurocognitive Impairments Associated With Severe Falciparum Malaria in Kenyan Children. J. Neurol. Neurosurg. Psychiatry 76, 476-481. doi: 10.1136/jnnp.2004.043893

Carter, J. A., Ross, A. J., Neville, B. G. R., Obiero, E., Katana, K., Mung'ala-Odera, V., et al. (2005b). Developmental Impairments Following Severe Falciparum Malaria in Children. Trop. Med. Int. Heal. 10, 3-10. doi: 10.1111/j.13653156.2004.01345.x

Chin, W., Contacos, P. G., Coatney, G. R., and Kimball, H. R. (1965). A Naturally Acquired Quotidian-Type Malaria in Man Transferable to Monkeys. Science 149, 865. doi: 10.1126/science.149.3686.865

Clarke, S. E., Rouhani, S., Diarra, S., Saye, R., Bamadio, M., Jones, R., et al. (2017). Impact of a Malaria Intervention Package in Schools on Plasmodium Infection, Anaemia and Cognitive Function in Schoolchildren in Mali: A Pragmatic Cluster-Randomised Trial. BMJ Glob. Heal. 2, e000182. doi: 10.1136/bmjgh2016-000182

Cohee, L. M., Opondo, C., Clarke, S. E., Halliday, K. E., Cano, J., Shipper, A. G., et al. (2020). Preventive Malaria Treatment Among School-Aged Children in Sub-Saharan Africa: A Systematic Review and Meta-Analyses. Lancet Glob. Heal. 8, e1499-e1511. doi: 10.1016/S2214-109X(20)30325-9

Cohen, I. R. (1992). The Cognitive Paradigm and the Immunological Homunculus. Immunol. Today 13, 490-494. doi: 10.1016/0167-5699(92)90024-2

Conroy, A. L., Datta, D., and John, C. C. (2019a). Causes Severe Malaria and Its Complications in Children. BMC Med. 17, 10-13. doi: 10.1186/s12916-0191291-z

Conroy, A. L., Opoka, R. O., Bangirana, P., Idro, R., Ssenkusu, J. M., Datta, D., et al. (2019b). Acute Kidney Injury Is Associated With Impaired Cognition and Chronic Kidney Disease in a Prospective Cohort of Children With Severe Malaria. BMC Med. 17, 98. doi: 10.1186/S12916-019-1332-7

Conroy, A. L., Opoka, R. O., Bangirana, P., Namazzi, R., Okullo, A. E., Georgieff, M. K., et al. (2021). Parenteral Artemisinins Are Associated With Reduced Mortality and Neurologic Deficits and Improved Long-Term Behavioral Outcomes in Children With Severe Malaria. BMC Med. 19, 168. doi: 10.1186/S12916-021-02033-1

Cox, F. E. (2010). History of the Discovery of the Malaria Parasites and Their Vectors. Parasites Vectors 3, 5. doi: 10.1186/1756-3305-3-5

Dai, M., Reznik, S. E., Spray, D. C., Weiss, L. M., Tanowitz, H. B., Gulinello, M., et al. (2010). Persistent Cognitive and Motor Deficits After Successful Antimalarial Treatment in Murine Cerebral Malaria. Microbes Infect. 12, 1198-1207. doi: 10.1016/j.micinf.2010.08.006

Daniel-Ribeiro, C. T., and Martins, Y. C. (2017). A Imagem Que Temos Das Coisas: O Uso De Imagens Internas Para o Reconhecimento Neural de Objetos do Mundo Real" in Imagens, Micróbios e Espelhos: Os Sistemas Imune e Nervoso e Nossa Relação Com o Ambiente (Rio de Janeiro, RJ: Fiocruz), 159-197.

De Miranda, A. S., Brant, F., Vieira, L. B., Rocha, N. P., Vieira, É.L.M., Rezende, G. H. S., et al. (2017). A Neuroprotective Effect of the Glutamate Receptor Antagonist MK801 on Long-Term Cognitive and Behavioral Outcomes Secondary to Experimental Cerebral Malaria. Mol. Neurobiol. 54, 7063-7082. doi: 10.1007/s12035-016-0226-3

De Miranda, A. S., Lacerda-Queiroz, N., de Carvalho Vilela, M., Rodrigues, D. H., Rachid, M. A., Quevedo, J., et al. (2011). Anxiety-Like Behavior and 
Proinflammatory Cytokine Levels in the Brain of C57BL/6 Mice Infected With Plasmodium Berghei (Strain ANKA). Neurosci. Lett. 491, 202-206. doi: 10.1016/j.neulet.2011.01.038

De Niz, M., and Heussler, V. T. (2018). Rodent Malaria Models: Insights Into Human Disease and Parasite Biology. Curr. Opin. Microbiol. 46, 93-101. doi: 10.1016/j.mib.2018.09.003

De Sousa, L. P., De Almeida, R. F., Ribeiro-Gomes, F. L., De Moura Carvalho, L. J., E Souza, T. M., De Souza, D. O. G., et al. (2018). Long-Term Effect of Uncomplicated Plasmodium Berghei ANKA Malaria on Memory and Anxiety-Like Behaviour in C57BL/6 Mice. Parasites Vectors 11. doi: 10.1186/ s13071-018-2778-8

De Sousa, L. P., Ribeiro-Gomes, F. L., de Almeida, R. F., Souza, T. M., Werneck, G. L., Souza, D. O., et al. (2021). Immune System Challenge Improves Recognition Memory and Reverses Malaria-Induced Cognitive Impairment in Mice. Sci. Rep. 11, 14857. doi: 10.1038/S41598-021-94167-8

Desruisseaux, M. S., Gulinello, M., Smith, D. N., Lee, S. H. C., Tsuji, M., Weiss, L. M., et al. (2008). Cognitive Dysfunction in Mice Infected With Plasmodium Berghei Strain ANKA. J. Infect. Dis. 197, 1621-1627. doi: 10.1086/587908

Dondorp, A. M., Fanello, C. I., Hendriksen, I. C., Gomes, E., Seni, A., Chhaganlal, K. D., et al. (2010). Artesunate Versus Quinine in the Treatment of Severe Falciparum Malaria in African Children (AQUAMAT): An Open-Label, Randomised Trial. Lancet 376, 1647-1657. doi: 10.1016/S0140-6736(10)61924-1

Dorovini-Zis, K., Schmidt, K., Huynh, H., Fu, W., Whitten, R. O., Milner, D., et al. (2011). The Neuropathology of Fatal Cerebral Malaria in Malawian Children. Am. J. Pathol. 178, 2146-2158. doi: 10.1016/j.ajpath.2011.01.016

Fernando, S. D., Gunawardena, D. M., Bandara, M. R. S. S., De Silva, D., Carter, R., Mendis, K. N., et al. (2003). The Impact of Repeated Malaria Attacks on the School Performance of Children. Am. J. Trop. Med. Hyg. 69, 582-588. doi: $10.4269 /$ ajtmh.2003.69.582

Fink, G., Olgiati, A., Hawela, M., Miller, J. M., and Matafwali, B. (2013). Association Between Early Childhood Exposure to Malaria and Children's Pre-School Development: Evidence From the Zambia Early Childhood Development Project. Malar. J. 12, 12. doi: 10.1186/1475-2875-12-12

Freeman, B. D., Martins, Y. C., Akide-Ndunge, O. B., Bruno, F. P., Wang, H., Tanowitz, H. B., et al. (2016). Endothelin-1 Mediates Brain Microvascular Dysfunction Leading to Long-Term Cognitive Impairment in a Model of Experimental Cerebral Malaria. PloS Pathog. 12, e1005477. doi: 10.1371/ JOURNAL.PPAT.1005477

Ghazanfari, N., Mueller, S. N., and Heath, W. R. (2018). Cerebral Malaria in Mouse and Man. Front. Immunol. 9, 2016. doi: 10.3389/fimmu.2018.02016

Grau, G. E., Bieler, G., Pointaire, P., De Kossodo, S., Tacchini-Cotier, F., Vassalli, P., et al. (1990). Significance of Cytokine Production and Adhesion Molecules in Malarial Immunopathology. Immunol. Lett. 25, 189-194. doi: 10.1016/01652478(90)90113-5

Guha, S. K., Sarkar, I., Patgaonkar, M., Banerjee, S., Mukhopadhyay, S., Sharma, S., et al. (2020). A History of Juvenile Mild Malaria Exacerbates Chronic StressEvoked Anxiety-Like Behavior, Neuroinflammation, and Decline of Adult Hippocampal Neurogenesis in Mice. J. Neuroimmunol. 348, 577363. doi: 10.1016/j.jneuroim.2020.577363

Guha, S. K., Tillu, R., Sood, A., Patgaonkar, M., Nanavaty, I. N., Sengupta, A., et al. (2014). Single Episode of Mild Murine Malaria Induces Neuroinflammation, Alters Microglial Profile, Impairs Adult Neurogenesis, and Causes Deficits in Social and Anxiety-Like Behavior. Brain. Behav. Immun. 42, 123-137. doi: 10.1016/j.bbi.2014.06.009

Gul, S., Ribeiro-Gomes, F. L., Moreira, A. S., Sanches, G. S., Conceição, F. G., Daniel-Ribeiro, C. T., et al. (2021). Whole Blood Transfusion Improves Vascular Integrity and Increases Survival in Artemether-Treated Experimental Cerebral Malaria. Sci. Rep. 11, 12077. doi: 10.1038/s41598-02191499-3

Hickson, M. R., Conroy, A. L., Bangirana, P., Opoka, R. O., Idro, R., Ssenkusu, J. M., et al. (2019). Acute Kidney Injury in Ugandan Children With Severe Malaria Is Associated With Long-Term Behavioral Problems. PloS One 14, e0226405. doi: 10.1371/JOURNAL.PONE.0226405

Hunt, N. H., Golenser, J., Chan-Ling, T., Parekh, S., Rae, C., Potter, S., et al. (2006). Immunopathogenesis of Cerebral Malaria. Int. J. Parasitol. 36, 569-582. doi: 10.1016/j.ijpara.2006.02.016

Idro, R., Carter, J. A., Fegan, G., Neville, B. G. R., and Newton, C. R. J. C. (2006). Risk Factors for Persisting Neurological and Cognitive Impairments
Following Cerebral Malaria. Arch. Dis. Child. 91, 142-148. doi: 10.1136/ adc. 2005.077784

Idro, R., Kakooza-Mwesige, A., Asea, B., Ssebyala, K., Bangirana, P., Opoka, R. O., et al. (2016). Cerebral Malaria Is Associated With Long-Term Mental Health Disorders: A Cross Sectional Survey of a Long-Term Cohort. Malar. J. 15, 184. doi: 10.1186/s12936-016-1233-6

Idro, R., Karamagi, C., and Tumwine, J. (2004). Immediate Outcome and Prognostic Factors for Cerebral Malaria Among Children Admitted to Mulago Hospital, Uganda. Ann. Trop. Paediatr. 24, 17-24. doi: 10.1179/ 027249304225013240

Idro, R., Marsh, K., John, C. C., and Newton, C. R. J. (2010). Cerebral Malaria: Mechanisms of Brain Injury and Strategies for Improved Neurocognitive Outcome. Pediatr. Res. 68, 267-274. doi: 10.1203/PDR.0b013e3181eee738

Jerne, N. K., and Cocteau, J. (1984). Idiotypic Networks and Other Preconceived Ideas. Immunol. Rev. 79, 5-24. doi: 10.1111/j.1600-065X.1984.tb00484.x

John, C. C., Bangirana, P., Byarugaba, J., Opoka, R. O., Idro, R., Jurek, A. M., et al. (2008). Cerebral Malaria in Children Is Associated With Long-Term Cognitive Impairment. Pediatrics 122, e92-e99. doi: 10.1542/peds.2007-3709

Josefsson, E., Bergquist, J., Ekman, R., and Tarkowski, A. (1996). Catecholamines Are Synthesized by Mouse Lymphocytes and Regulate Function of These Cells by Induction of Apoptosis. Immunology 88, 140-146. doi: 10.1046/j.13652567.1996.d01-653.x

Kariuki, S. M., Ikumi, M., Ojal, J., Sadarangani, M., Idro, R., Olotu, A., et al. (2011). Acute Seizures Attributable to Falciparum Malaria in an Endemic Area on the Kenyan Coast. Brain 134, 1519-1528. doi: 10.1093/BRAIN/AWR051

Lacerda-Queiroz, N., Rodrigues, D. H., Vilela, M. C., de Miranda, A. S., Amaral, D. C. G., da Camargos, E. R. S., et al. (2010). Inflammatory Changes in the Central Nervous System are Associated With Behavioral Impairment in Plasmodium Berghei (Strain ANKA)-Infected Mice. Exp. Parasitol. 125, 271-278. doi: 10.1016/j.exppara.2010.02.002

Langfitt, J. T., McDermott, M. P., Brim, R., Mboma, S., Potchen, M. J., Kampondeni, S. D., et al. (2019). Neurodevelopmental Impairments 1 Year After Cerebral Malaria. Pediatrics 143, e20181026. doi: 10.1542/peds.2018-1026

Lau, C. K. Y., Turner, L., Jespersen, J. S., Lowe, E. D., Petersen, B., Wang, C. W., et al. (2015). Structural Conservation Despite Huge Sequence Diversity Allows EPCR Binding by the PfEMP1 Family Implicated in Severe Childhood Malaria. Cell Host Microbe 17, 118-129. doi: 10.1016/J.CHOM.2014.11.007

Laverse, E., Nashef, L., and Brown, S. (2013). Neurocognitive Sequelae Following Hippocampal and Callosal Lesions Associated With Cerebral Malaria in an Immunenaive Adult. Postgrad. Med. J. 89, 671-672. doi: 10.1136/ postgradmedj-2013-131758

Lell, B., Köhler, C., Wamola, B., Olola, C. H., Kivaya, E., Kokwaro, G., et al. (2010), Pentoxifylline as an Adjunct Therapy in Children With Cerebral Malaria. Malar. J. 9, 368. doi: 10.1186/1475-2875-9-368

Lima, M. N., Oliveira, H. A., Fagundes, P. M., Estato, V., Silva, A. Y. O., Freitas, R. J. R. X., et al. (2020). Mesenchymal Stromal Cells Protect Against Vascular Damage and Depression-Like Behavior in Mice Surviving Cerebral Malaria. Stem Cell Res. Ther. 11, 367. doi: 10.1186/s13287-020-01874-6

Li, Q., Qi, F., Yang, J., Zhang, L., Gu, H., Zou, J., et al. (2015). Neonatal Vaccination With Bacillus Calmette-Guérin and Hepatitis B Vaccines Modulates Hippocampal Synaptic Plasticity in Rats. J. Neuroimmunol. 288, 1-12. doi: 10.1016/j.jneuroim.2015.08.019

Li, C., Seixas, E., and Langhorne, J. (2001). Rodent Malaria: The Mouse as a Model for Understanding Immune Responses and Pathology Induced by the Erythrocytic Stages of the Parasite. Med. Microbiol. Immunol. 189, 115-126. doi: 10.1007/s430-001-8017-8

Li, Q., Zhang, Y., Zou, J., Qi, F., Yang, J., Yuan, Q., et al. (2016). Neonatal Vaccination With Bacille Calmette-Guérin Promotes the Dendritic Development of Hippocampal Neurons. Hum. Vaccines Immunother. 12, 140-149. doi: 10.1080/21645515.2015.1056954

Lou, J., Lucas, R., and Grau, G. E. (2001). Pathogenesis of Cerebral Malaria: Recent Experimental Data and Possible Applications for Humans. Clin. Microbiol. Rev. 14, 810-820. doi: 10.1128/CMR.14.4.810-820.2001

Martins, Y. C., Freeman, B. D., Akide Ndunge, O. B., Weiss, L. M., Tanowitz, H. B., and Desruisseaux, M. S. (2016). Endothelin-1 Treatment Induces an Experimental Cerebral Malaria-Like Syndrome in C57BL/6 Mice Infected With Plasmodium Berghei NK65. Am. J. Pathol. 186, 2957-2969. doi: 10.1016/ j.ajpath.2016.07.020 
Martins, Y. C., Smith, M. J., Pelajo-Machado, M., Werneck, G. L., Lenzi, H. L., Daniel-Ribeiro, C. T., et al. (2009). Characterization of Cerebral Malaria in the Outbred Swiss Webster Mouse Infected by Plasmodium Berghei ANKA. Int. J. Exp. Pathol. 90, 119-130. doi: 10.1111/j.1365-2613.2008.00622.x

Martins, Y. C., Werneck, G. L., Carvalho, L. J., Silva, B. P. T., Andrade, B. G., Souza, T. M., et al. (2010). Algorithms to Predict Cerebral Malaria in Murine Models Using the SHIRPA Protocol. Malar. J. 9. doi: 10.1186/1475-2875-9-85

McDonald, C. R., Cahill, L. S., Ho, K. T., Yang, J., Kim, H., Silver, K. L., et al. (2015). Experimental Malaria in Pregnancy Induces Neurocognitive Injury in Uninfected Offspring via a C5a-C5a Receptor Dependent Pathway. PloS Pathog. 11, e1005140. doi: 10.1371/journal.ppat.1005140

McKenna, F., McLaughlin, P. J., Lewis, B. J., Sibbring, G. C., Cummerson, J. A., Bowen-Jones, D., et al. (2002). Dopamine Receptor Expression on Human Tand B-Lymphocytes, Monocytes, Neutrophils, Eosinophils and NK Cells: A Flow Cytometric Study. J. Neuroimmunol. 132, 34-40. doi: 10.1016/S01655728(02)00280-1

Medana, I. M., Day, N. P., Hien, T. T., Mai, N. T. H., Bethell, D., Phu, N. H., et al. (2002). Axonal Injury in Cerebral Malaria. Am. J. Pathol. 160, 655-666. doi: 10.1016/S0002-9440(10)64885-7

Mwanga-Amumpaire, J., Carroll, R. W., Baudin, E., Kemigisha, E., Nampijja, D., Mworozi, K., et al. (2015). Inhaled Nitric Oxide as an Adjunctive Treatment for Cerebral Malaria in Children: A Phase II Randomized Open-Label Clinical Trial. Open Forum Infect. Dis. 2, ofv132. doi: 10.1093/ofid/ofv111

Nankabirwa, J., Wandera, B., Kiwanuka, N., Staedke, S. G., and Kamya, M. R. (2013). And Brooker, sAsymptomatic Plasmodium Infection and Cognition Among Primary Schoolchildren in a High Malaria Transmission Setting in Uganda Am. J. Trop. Med. Hyg. 88, 1102-1108. doi: 10.4269/ajtmh.12-0633

Neres, R., Marinho, C. R. F., Gonçalves, L. A., Catarino, M. B., and PenhaGonçalves, C. (2008). Pregnancy Outcome and Placenta Pathology in Plasmodium Berghei ANKA Infected Mice Reproduce the Pathogenesis of Severe Malaria in Pregnant Women. PloS One 3, e1608. doi: 10.1371/ journal.pone.0001608

Oluwayemi, I. O., Brown, B. J., Oyedeji, O. A., and Oluwayemi, M. A. (2013). Neurological Sequelae in Survivors of Cerebral Malaria. Pan Afr. Med. J. 15, 88. doi: 10.11604/pamj.2013.15.88.1897

Ouma, B. J., Bangirana, P., Ssenkusu, J. M., Datta, D., Opoka, R. O., Idro, R., et al. (2021). Plasma Angiopoietin-2 Is Associated With Age-Related Deficits in Cognitive Sub-Scales in Ugandan Children Following Severe Malaria. Malar. J. 20, 17. doi: 10.1186/s12936-020-03545-6

Peixoto, B., and Kalei, I. (2013). To Characterize the Neurocognitive Sequelae of Cerebral Malaria (CM) in an Adult Sample of the City of Benguela, Angola. Asian Pac. J. Trop. Biomed. 3, 532-535. doi: 10.1016/S2221-1691(13)60108-2

Pert, C. B., Ruff, M. R., Weber, R. J., and Herkenham, M. (1985). Neuropeptides and Their Receptors: A Psychosomatic Network. J. Immunol. 135, 820s-826s.

Porta, J., Carota, A., Pizzolato, G. P., Wildi, E., Widmer, M. C., Margairaz, C., et al. (1993). Immunopathological Changes in Human Cerebral Malaria. Clin. Neuropathol. 12 (3), 142-146.

Potter, S., Chan-Ling, T., Ball, H. J., Mansour, H., Mitchell, A., Maluish, L., et al. (2006). Perforin Mediated Apoptosis of Cerebral Microvascular Endothelial Cells During Experimental Cerebral Malaria. Int. J. Parasitol. 36, 485-496. doi: 10.1016/j.ijpara.2005.12.005

Qi, F., Zuo, Z., Yang, J., Hu, S., Yang, Y., Yuan, Q., et al. (2017). Combined Effect of BCG Vaccination and Enriched Environment Promote Neurogenesis and Spatial Cognition via a Shift in Meningeal Macrophage M2 Polarization. J. Neuroinflamm. 14, 32. doi: 10.1186/s12974-017-0808-7

Reis, P. A., Comim, C. M., Hermani, F., Silva, B., Barichello, T., Portella, A. C., et al. (2010). Cognitive Dysfunction Is Sustained After Rescue Therapy in Experimental Cerebral Malaria, and Is Reduced by Additive Antioxidant Therapy. PloS Pathog. 6, e1000963. doi: 10.1371/journal.ppat.1000963

Reverchon, F., Mortaud, S., Sivoyon, M., Maillet, I., Laugeray, A., Palomo, J., et al. (2017). IL-33 Receptor ST2 Regulates the Cognitive Impairments Associated With Experimental Cerebral Malaria. PloS Pathog. 13, e1006322. doi: 10.1371/ journal.ppat.1006322

Richardson, E. D., Varney, N. R., Roberts, R. J., Springer, J. A., and Wood, PS (1997). Long-Term Cognitive Sequelae of Cerebral Malaria in Vietnam Veterans. Appl. Neuropsychol. 4, 238-243. doi: 10.1207/s15324826an0404_5

Sankowski, R., Mader, S., and Valdés-Ferrer, S. I. (2015). Systemic Inflammation and the Brain: Novel Roles of Genetic, Molecular, and Environmental Cues as
Drivers of Neurodegeneration. Front. Cell. Neurosci. 9, 28. doi: 10.3389/ FNCEL.2015.00028

Sawada, M., Itoh, Y., Suzumura, A., and Marunouchi, T. (1993). Expression of Cytokine Receptors in Cultured Neuronal and Glial Cells. Neurosci. Lett. 160, 131-134. doi: 10.1016/0304-3940(93)90396-3

Scaccabarozzi, D., Deroost, K., Corbett, Y., Lays, N., Corsetto, P., Salè, F. O., et al. (2018). Differential Induction of Malaria Liver Pathology in Mice Infected With Plasmodium Chabaudi AS or Plasmodium Berghei NK65. Malar. J. 17, 18. doi: 10.1186/s12936-017-2159-3

Schiess, N., Villabona-Rueda, A., Cottier, K. E., Huether, K., Chipeta, J., and Stins, M. F. (2020). Pathophysiology and Neurologic Sequelae of Cerebral Malaria. Malar. J. 19, 266. doi: 10.1186/s12936-020-03336-Z

Serghides, L., McDonald, C. R., Lu, Z., Friedel, M., Cui, C., Ho, K. T., et al. (2014). Ppary Agonists Improve Survival and Neurocognitive Outcomes in Experimental Cerebral Malaria and Induce Neuroprotective Pathways in Human Malaria. PloS Pathog. 10, e1003980. doi: 10.1371/JOURNAL.PPAT.1003980

Severe Malaria (2014). Trop. Med. Int. Health 19 (Suppl 1), 7-131. doi: 10.1111/ TMI.12313_2

Singh, B., Sung, L. K., Matusop, A., Radhakrishnan, A., Shamsul, S. S. G., CoxSingh, J., et al. (2004). A Large Focus of Naturally Acquired Plasmodium Knowlesi Infections in Human Beings. Lancet 363, 1017-1024. doi: 10.1016/ S0140-6736(03)14713-7

Ssenkusu, J. M., Hodges, J. S., Opoka, R. O., Idro, R., Shapiro, E., John, C. C., et al. (2016). Long-Term Behavioral Problems in Children With Severe Malaria. Pediatrics 138, e20161965. doi: 10.1542/peds.2016-1965

Sutherland, C. J., Tanomsing, N., Nolder, D., Oguike, M., Jennison, C., Pukrittayakamee, S., et al. (2010). Two Nonrecombining Sympatric Forms of the Human Malaria Parasite Plasmodium Ovale Occur Globally. J. Infect. Dis. 201, 1544-1550. doi: 10.1086/652240

Ta, T. H., Hisam, S., Lanza, M., Jiram, A. I., Ismail, N., and Rubio, J. M. (2014). First Case of a Naturally Acquired Human Infection With Plasmodium Cynomolgi. Malar. J. 13, 1-7. doi: 10.1186/1475-2875-13-68

Tapajós, R., Castro, D., Melo, G., Balogun, S., James, M., Pessoa, R., et al. (2019). Malaria Impact on Cognitive Function of Children in a Peri-Urban Community in the Brazilian Amazon. Malar. J. 18, 173. doi: 10.1186/ s12936-019-2802-2

Taylor, T. E., Fu, W. J., Carr, R. A., Whitten, R. O., Mueller, J. G., Fosiko, N. G., et al. (2004). Differentiating the Pathologies of Cerebral Malaria by Postmortem Parasite Counts. Nat. Med. 10, 143-145. doi: 10.1038/NM986

Thuilliez, J., Sissoko, M. S., Toure, O. B., Kamate, P., Berthélemy, J. C., and Doumbo, O. K. (2010). Malaria and Primary Education in Mali: A Longitudinal Study in the Village of Donéguébougou. Soc Sci. Med. 71, 324334. doi: 10.1016/j.socscimed.2010.02.027

Van Den Steen, P. E., Geurts, N., Deroost, K., Van Aelst, I., Verhenne, S., Heremans, H., et al. (2010). Immunopathology and Dexamethasone Therapy in a New Model for Malaria-Associated Acute Respiratory Distress Syndrome. Am. J. Respir. Crit. Care Med. 181, 957-968. doi: 10.1164/ rccm.200905-0786OC

Van Hensbroek, M. B., Palmer, A., Onyiorah, E., Schneider, G., Jaffar, S., Dolan, G., et al. (1996). The Effect of a Monoclonal Antibody to Tumor Necrosis Factor on Survival From Childhood Cerebral Malaria. J. Infect. Dis. 174, 10911097. doi: 10.1093/infdis/174.5.1091

Varney, N. R., Roberts, R. J., Springer, J. A., Connell, S. K., and Wood, P. S. (1997). The Neuropsychiatric Sequelae of Cerebral Malaria in Vietnam Veterans. J. Nerv. Ment. Dis. 185, 695-703. doi: 10.1097/00005053-199711000-00008

Varo, R., Crowley, V. M., Sitoe, A., Madrid, L., Serghides, L., Kain, K. C., et al. (2018). Adjunctive Therapy for Severe Malaria: A Review and Critical Appraisal. Malar. J. 17, 47. doi: 10.1186/s12936-018-2195-7

Vitor-Silva, S., Reyes-Lecca, R. C., Pinheiro, T. R. A., and Lacerda, M. V. G. (2009). Malaria Is Associated With Poor School Performance in an Endemic Area of the Brazilian Amazon. Malar. J. 8, 230. doi: 10.1186/1475-2875-8-230

Vorasan, N., Pan-Ngum, W., Jittamala, P., Maneeboonyang, W., Rukmanee, P., and Lawpoolsri, S. (2015). Long-Term Impact of Childhood Malaria Infection on School Performance Among School Children in a Malaria Endemic Area Along the ThaiMyanmar Border. Malar. J. 14, 401. doi: 10.1186/s12936-015-0917-7

Warrell, D. A., Looareesuwan, S., Warrell, M. J., Kasemsarn, P., Intaraprasert, R., Bunnag, D., et al. (1982). Dexamethasone Proves Deleterious in Cerebral Malaria. N. Engl. J. Med. 306, 313-319. doi: 10.1056/nejm198202113060601 
Witschkowski, J., Behrends, J., Frank, R., Eggers, L., von Borstel, L., Hertz, D., et al. (2020). BCG Provides Short-Term Protection From Experimental Cerebral Malaria in Mice. Vaccines 8, 1-15. doi: 10.3390/VACCINES8040745

World Health Organization. (2020). World Malaria Report 2020: 20 Years of Global Progress and Challenges (Geneva: World Health Organization Licence: CC BY-NC-SA 3.0 IGO). Available at: https://www.who.int/publications/i/ item/9789240015791 [Accessed November 30, 2021]

Xia, Y., Qi, F., Zou, J., Yang, J., and Yao, Z. (2014). Influenza Vaccination During Early Pregnancy Contributes to Neurogenesis and Behavioral Function in Offspring. Brain. Behav. Immun. 42, 212-221. doi: 10.1016/j.bbi.2014.06.202

Yang, Y., He, Z., Xing, Z., Zuo, Z., Yuan, L., Wu, Y., et al. (2020). Influenza Vaccination in Early Alzheimer's Disease Rescues Amyloidosis and Ameliorates Cognitive Deficits in APP/PS1 Mice by Inhibiting Regulatory T Cells. J. Neuroinflamm. 17, 65. doi: 10.1186/s12974-020-01741-4

Yang, J., Qi, F., Gu, H., Zou, J., Yang, Y., Yuan, Q., et al. (2016). Neonatal BCG Vaccination of Mice Improves Neurogenesis and Behavior in Early Life. Brain Res. Bull. 120, 25-33. doi: 10.1016/j.brainresbull.2015.10.012
Conflict of Interest: The authors declare that the research was conducted in the absence of any commercial or financial relationships that could be construed as a potential conflict of interest.

Publisher's Note: All claims expressed in this article are solely those of the authors and do not necessarily represent those of their affiliated organizations, or those of the publisher, the editors and the reviewers. Any product that may be evaluated in this article, or claim that may be made by its manufacturer, is not guaranteed or endorsed by the publisher.

Copyright (๑) 2022 Rosa-Gonçalves, Ribeiro-Gomes and Daniel-Ribeiro. This is an open-access article distributed under the terms of the Creative Commons Attribution License (CC BY). The use, distribution or reproduction in other forums is permitted, provided the original author(s) and the copyright owner(s) are credited and that the original publication in this journal is cited, in accordance with accepted academic practice. No use, distribution or reproduction is permitted which does not comply with these terms. 